\title{
Research on Financial Support Measures in Guizhou New Urbanization Construction
}

\author{
Hongmei Zhang ${ }^{1,2,3}$ Mei Pang ${ }^{1,2,3}$ Yingpeng Lai ${ }^{4}$ \\ ${ }^{1}$ Guizhou University of Finance and Economics, Institute of Finance \\ ${ }^{2}$ Guizhou Institution for Technology Innovation \& Entrepreneurship Investment \\ ${ }^{3}$ Guizhou Institute of Urban Economics and Development Guiyang Guizhou 550025, \\ China \\ ${ }^{4}$ Agricultural Bank of China branch in Guizhou Province
}

\begin{abstract}
The development of new urbanization will bring huge financing needs in the fields of public facilities and services, and financial support will directly affect the orderly advancement of urbanization. What is the degree of financial support and the extent to which the new urbanization is supported is essential to the improvement of the new urbanization level and quality. In this paper, through the combing of the new urbanization and financial support of the relevant literature, design the relevant index system, select the 2006-2015 statistical data for empirical research. First, we use the method of entropy to measure the overall level of Guizhou's new urbanization. We use the principal component regression method to quantitatively measure the degree of financial support in urbanization construction and analyze its internal causes. Finally, from the point of view of financial supply, Related countermeasures and suggestions.
\end{abstract}

\section{Keywords}

Financial support; New urbanization; City integration

\section{贵州新型城镇化建设中的金融支持测度研究}

\author{
张红梅 $1,2,3$ 庞梅 ${ }^{1,2,3}$ 赖应鹏 4 \\ ${ }^{1}$ 贵州财经大学, 金融学院 \\ 2 贵州科技创新创业投资研究院 \\ ${ }^{3}$ 贵州城镇经济与发展研究院, 贵州贵阳 550025 \\ ${ }^{4}$ 中国农业银行贵州省分行, 贵州贵阳 550003
}

\begin{abstract}
摘要: 新型城镇化发展会带来公共设施和服务等领域的巨大融资需求, 而金融支持直接影响 着城镇化的有序推进。金融在哪些环节及多大程度上支持着新型城镇化，对新型城镇化水平 和质量的提高至关重要。本文通过梳理新型城镇化和金融支持的相关文献，设计相关指标体 系, 选取 2006-2015 年的统计数据进行实证研究。首先以熵值法衡量出贵州新型城镇化的整 体水平; 再运用主成分回归法对城镇化建设中的金融支持程度进行量化测度，并对其内在原 因进行分析; 最后从金融供给角度出发, 提出相关的对策建议。
\end{abstract}


关键词: 金融支持; 新型城镇化; 产城融合

\section{1. 引言}

新型城镇化是我国经济社会发展 的重大战略部署, 也是我国 “新四 化” 建设的重要内容, 更是优化区域 二元格局的根本举措。2014 年 3 月, 我国首次发布了《国家新型城镇化 （2014－2020 年）》规划书，对未来 6 年的新型城镇化建设任务作出了中长 期的规划和部署。新型城镇化坚持 “以人为本”, 以产业为支撑, 以实 现城乡基础设施一体化和公共服务均 等化为目标，其实质就是人口迁移、 产业结构及空间地理结构升级转换的 过程。金融作为国民经济发展的重要 组成部分, 金融支持对新型城镇化建 设至关重要。

贵州地区城镇化水平低、底子 薄、融资能力弱使得资金缺口问题更 为凸显。为此, 推动贵州金融与城镇 化的良性互动, 以金融之力提高贵州 新型城镇化水平和质量, 是项极具战 略意义的研究课题。本文将新型城镇 ${ }^{1}$ 化从人口、产业及空间结构三方面细

${ }^{1}$ 基金项目: 本文由贵州省科技计划项目 （黔科合基础[2016]1534-4 号）资助, 项目 名称: 贵州新型城镇化金融支持效率研 究。

作者简介: 张红梅, 教授、硕士生导师, 任职于贵州财经大学金融学院, 研究方 向：金融与区域发展、创业投资、风险分 析与管理。Email：754560989@qq.com。 庞梅, 女, 贵州财经大学金融学院研究生 硕士。贵州财经大学在读研究生, 研究方 向: 金融与区域发展、创业投资、风险分 析与管理。Email: 779360357@qq.com。 赖应鹏, 男, 现就职于中国农业银行贵州 省分行公司大客户部任一部经理。Email: 7894859@qq.com
分为人口城镇化、产业城镇化和空间 城镇化; 以金融效率、金融结构和金 融规模下的 6 个指标为因变量, 采用 主成分分析等方法, 对新型城镇化建 设中的金融支持程度进行量化测度。 为政府政策的制定及各类市场主体在 贵州新型城镇化建设中金融资本的投 入提供着力点和切入点, 实现资本投 入的最大效用。

\section{2. 文献回顾}

\section{1 有关新型城镇化的研究综述}

新型城镇化内涵方面。倪鹏飞 (2013) ${ }^{[1]}$ 认为, 新型城镇化以科学发 展观为指导方针, 以 “全面、协调、 可持续发展” 为原则, 以人口城镇化 为核心内容, 以信息化、农业产业化 和工业化为动力, 以 “内涵增长” 为 发展方式, 以“政府引导、市场运 作” 为机制保障, 走可持续发展道 路, 建设城乡一体的城市中国。新型 城镇化发展方向方面。吴福象 (2013) ${ }^{[2]}$ 提出创新驱动型城镇化发展 战略, 通过要素空间集聚, 促进产业 优化升级, 形成人才与产业双向互 动, 促进城镇化快速发展。杨充霖

(2014) ${ }^{[3]}$ 认为新型城镇化是以公平和 效率相统一为目标的资源空间配置过 程。新型城镇化发展路径方面。陶友 之 (2013) ${ }^{[4]}$ 从区域发展的角度分析, 认为新型城镇化应做到差别推进, 具 体包括西部实行集中连片模式, 中部 实行壮市强镇模式, 东部实行强市进 化模式。王素斋 (2013) ${ }^{[5]}$ 提出新型城 镇化的发展应该从六个方面入手: 统 筹规划, 科学发展; 建立健全政府引 导机制; 调整产业结构, 促进四化良 性发展; 建构科学的城镇化发展体 
系; 进行体制改革, 消除发展障碍; 推进新农村建设与城镇化的协调发 展。

\section{2 金融支持与新型城镇化关系的研究 综述}

金融支持与新型城镇化作用机制 的研究。黄国平 (2013) ${ }^{[6]}$ 认为, 完善 金融服务体系才能真正的促进新型城 镇化的发展。彭克强 (2014) ${ }^{[7]}$ 提出深 化融资体制改革，逐步实现投融资市 场化, 激发金融支持城镇化巨大潜 能。

金融支持与新型城镇化建设的实 证研究。陈志伟 (2014) ${ }^{[8]}$ 利用 20012012 年河南省 17 个地级市的面板数 据, 采用 GMM 估计、格兰杰因果检验 等计量方法，研究表明金融发展在短 期内显著促进户籍人口城镇化进程。 罗琼（2016） ${ }^{[9]}$ 运用 1998-2012 年中国 城镇化发展数据和中国金融发展数 据，建立 VAR 模型实证研究不同金融 种类对新型城镇化各个方面的影响及 其差异。研究表明, 金融支持与新型 城镇化之间存在稳定的长期协整关 系。李文（2017） ${ }^{[10]}$ 等选取 2006 2014 年西部 11 省区相关数据, 运用时 序全局主成分分析对新型城镇化发展 水平进行综合测度; 并运用面板数据 模型，实证分析金融对西部各省支持 力度。发现西部各省新型城镇化发展 水平普遍较低, 金融对新型城镇化建 设支持力度不足。

金融支持促进新型城镇化建设路 径选择的研究。方显仓（2013） ${ }^{[11]}$ 认 为应建立以政策性金融为主导、国有 商业金融为辅助，合作金融和中小型 金融为主体的金融组织体系, 以改善 我国金融机构有效供给不足的情况。 邱俊杰 (2013) ${ }^{[12]}$ 认为今后城镇化发 展建立以市场为主导的资本形成机 制, 准确识别新型城镇化关键投资领
域, 如新能源领域、环保领域、健康 领域及移动互联网领域等。

\section{3. 分析方法及模型建立}

（1）改进熵值法。由于新型城镇化强 调以人为本、产城互动、可持续发展 的理念, 不能用单一指标来衡量, 因 此，本文采用主客观赋权法相结合的 改进熵值法从人口、产业、空间城镇 化三层面全方位、多角度衡量新型城 镇化的整体发展情况, 以弥补单一城 镇化指标的缺陷。改进熵值法的基本 原理如下:

(1)假设选取 $n$ 个测度对象, $m$ 项指标, $X_{i j}$ 是第 $i$ 个测度对象的第 $j$ 项指标数

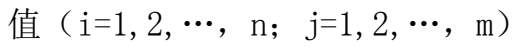
选用极值法对数据做无量纲化处理。 正向指标:

$$
X_{i j}=\frac{X_{i j}-\min \left(X_{1 j}, X_{2 j}, \cdots, X_{n j}\right)}{\max \left(X_{1 j}, X_{2 j}, \cdots, X_{n j}\right)-\min \left(X_{1 j}, X_{2 j}, \cdots, X_{n j}\right)}+1
$$

负向指标:

$X_{i j}=\frac{\max \left(X_{1 j}, X_{2 j}, \cdots, X_{n j}\right)-X_{i j}}{\max \left(X_{1 j}, X_{2 j}, \cdots, X_{n j}\right)-\min \left(X_{1 j}, X_{2 j}, \cdots, X_{n j}\right)}+1$

(2)计算第 $\mathrm{j}$ 项指标、第 $\mathrm{i}$ 测度对象 $X_{\mathrm{i}, \mathrm{j}}$ 的比重为:

$$
P_{i j}=\frac{X_{i j}}{\sum_{i=1}^{n} X_{i j}}
$$

(3)第 $\mathrm{j}$ 项指标的熵值为:

$$
E_{j}=-K \sum_{i=1}^{n} P_{i j} \operatorname{Ln}\left(P_{i j}\right) \quad K=\frac{1}{\operatorname{Ln}(n)}
$$

(4)对差异性系数 $\mathrm{D}_{\mathrm{j}}$ 进行计算, 得出第 $\mathrm{j}$ 项指标的权重 $W_{j}$ :

$$
\begin{gathered}
D_{j}=1-E_{j} \\
W_{j}=\frac{D_{j}}{\sum_{j=1}^{m} D_{j}}
\end{gathered}
$$

(5)新型城镇化水平综合指标值为:

$$
z_{i}=\sum_{j=1}^{m} W_{j} \cdot P_{i j}
$$


（2）主成分回归分析法。考虑到所选 取的自变量可能具有某种相关性, 会 影响回归分析的结果。而主成分回归 法是处理自相关问题的主要方法，所 以本文以测度出的城镇化综合水平为 因变量, 6 个金融指标为自变量, 运用 主成分回归法构建回归方程，基

本原理如下:

(1) 将 $\mathrm{n}$ 个标准化自变量做主成分分 析, 从获得的 $\mathrm{p}$ 个主成分 $\mathrm{F}_{1}, \mathrm{~F}_{2}, \ldots$, FP 中选取方差贡献率大于 $80 \%$ 的前 $\mathrm{q}$ 个主成分。

(2)利用普通最小二乘法, 将 $\mathrm{q}$ 个主成 分 $F_{1}, F_{2}, \ldots, F_{q}$ 与因变量做回归分 析, 回归方程如下:

$$
\hat{Y}=\hat{\beta}_{1} F_{1}+\hat{\beta}_{2} F_{2}+\cdots \hat{\beta}_{q} F_{q}
$$

(3)每个主成分 $F_{1}, F_{2}, \ldots, F p$ 都是关于 自变量 $\mathrm{X}_{1}, \mathrm{X}_{2}, \ldots, \mathrm{X}_{\mathrm{P}}$ 的线性组合, 通 过转化得到的最终回归模型为:

$$
\hat{Y}=\hat{\alpha}_{1} X_{1}+\hat{\alpha}_{2} X_{2}+\cdots+\hat{\alpha}_{p} X_{p}
$$

\section{4. 实证分析}

为了深入分析金融在多大程度上 支持贵州新型城镇化及如何实现二者 的良性互动, 本文以改进熵值法测算 出贵州新型城镇化的整体水平, 并运 用主成分回归法建立多变量的回归模 型来测度其城镇化进程中的金融支持 程度。

\section{1 指标选取与数据说明}

基于对金融发展与新型城镇化间 相关文献的梳理，本文从金融供给的 效率、结构、规模选取 6 个相应指 标, 并从人口、产业、空间城镇化选 取 8 个相应指标（如表 1、表 2)。样 本数据主要来源于《国家统计局》

《贵州统计局》等, 选取了贵州省城 镇化进程中 2006-2015 年的统计数 据, 并经过整理和汇总得到。实证分 析过程主要通过软件 Matlab7.0 和 SPSS22. 0 来完成。

\section{2 实证分析过程}

\section{(1) 新型城镇化综合发展水平测度}

以 2015 年的指标数据为例, 运用 改进熵值法测算的城镇化各指标及综 合指标的权重值如表 2 所示，同理可 得出 2006-2014 年的指标权重值。图 1 是 2006-2015 年贵州省人口、产业、 空间城镇化对城镇化综合水平的贡献 程度, 可知贵州城镇化发展水平一直 呈上升趋势。相比而言，近年来空间 城镇化和人口城镇化对城镇化建设的 影响力有所提高, 而产业城镇化对城 镇化综合发展水平的作用微乎其微, 需要进一步协调好三大产业的关系, 推动产城融合化发展。

\begin{tabular}{|c|c|c|}
\hline 目标层 & 二级指标 (\%) & 指标表示 \\
\hline \multirow{6}{*}{$\begin{array}{c}\text { 金融 } \\
\text { 支持 } \\
\text { 指标 } \\
\text { X }\end{array}$} & 金融机构存贷款转化率 & $X_{1}$ \\
\hline & 金融业对 GDP 的贡献率 & $X_{2}$ \\
\hline & 金融机构存贷款总额占 GDP 的比值 & $\mathrm{X}_{3}$ \\
\hline & 全社会固定资产投资中国内贷款占比 & $X_{4}$ \\
\hline & 城镇固定资产投资额占存款额的比值 & $\mathrm{X}_{5}$ \\
\hline & 中长期贷款占贷款余额的比值 & $X_{6}$ \\
\hline
\end{tabular}

表 1 金融支持指标体系

\begin{tabular}{|c|c|c|c|}
\hline 目标层 & 一级指标 & 二级指标（权重） & 指标属性 \\
\hline \multirow{8}{*}{$\begin{array}{c}\text { 新型城 } \\
\text { 镇化综 } \\
\text { 合发展 } \\
\text { 水平 Y } \\
(1.811 \\
)\end{array}$} & \multirow{3}{*}{$\begin{array}{l}\text { 人口城镇化 } \\
(0.739)\end{array}$} & 城镇化率\%（0.267） & 正指标 \\
\hline & & $\begin{array}{c}\text { 非农产业从业人员比重\% } \\
(0.224)\end{array}$ & 正指标 \\
\hline & & 人均 GDP (元) (0.248) & 正指标 \\
\hline & \multirow{2}{*}{$\begin{array}{c}\text { 产业城镇化 } \\
(0.256)\end{array}$} & 第三产业贡献率\%（0.119） & 正指标 \\
\hline & & $\begin{array}{c}\text { 非农产业对 GDP 增长的拉 } \\
\text { 动 }(0.137)\end{array}$ & 正指标 \\
\hline & \multirow{3}{*}{$\begin{array}{l}\text { 空间城镇化 } \\
(0.816)\end{array}$} & $\begin{array}{c}\text { 社区服务机构覆盖率\% } \\
(0.342)\end{array}$ & 正指标 \\
\hline & & $\begin{array}{c}\text { 人均城市道路面积 (平方 } \\
\text { 米) }(0.272)\end{array}$ & 正指标 \\
\hline & & $\begin{array}{c}\text { 城镇建成区绿化覆盖率\% } \\
(0.202))\end{array}$ & 正指标 \\
\hline
\end{tabular}

表 2 新型城镇化指标体系 


\section{（2）新型城镇化建设中的金融支持测 度}

(1)相关性和共线性分析。通过相关性 分析可知自变量和城镇化综合水平之 间存在线性相关性，说明变量之间可 以建立回归方程, 并且自变量之间也 存在一定的相关性，因为金融发展指 标本身就是相互影响的。此外, 通过 共线性诊断也可进一步确定自变量间 存在共线性问题，这会造成回归估计 的偏差, 不利于直接进行回归处理, 有必要通过主成分分析法来解决这一 问题。

(2)主成分分析。为消除异方差问题， 先将变量作标准化处理。由于 $\mathrm{KMO}$ 值 是 0.719 , 可以进行主成分分析。从表 3 可知前两个主成分解释了所有变量的 $87.601 \%$, 且特征值都大于 1 , 故只需 提取前两个主成分就可达到降维的效 果。主成分 $F_{1}$ 和 $F_{2}$ 的方程式由初始矩 阵系数与对应特征根的平方根相除得 到 $\left(X^{*}{ }_{1}, X^{*}{ }_{2}, \ldots, X^{*}{ }_{7}\right.$ 代表标准化变 量）。由（1）式和（2）式可知, 主 成分 $F_{1}$ 主要是对除 $X_{1}$ 以外变量的反 映, 称之为主要金融指标; $F_{2}$ 则主要 是对变量 $\mathrm{X}_{1}$ 的反映, 称之为次要金融 指标。

$F_{1}=-0.211 X_{1}^{*}+0.475 X_{2}^{*}+0.415 X_{3}^{*}$

$-0.442 X_{4}^{*}+0.444 X_{5}^{*}+0.406 X_{6}^{*}$

$F_{2}=0.821 X_{1}^{*}-0.019 X_{2}^{*}+0.270 X_{3}^{*}$

$-0.185 X_{4}^{*}+0.283 X_{5}^{*}-0.330 X_{6}^{*}$

(3)主成分回归分析。由主成分得分取 代原变量与标准化变量 $\mathrm{Y} *$ 作多元回归 处理 (其中主成分得分 $=$ 因子得分*特 征根的平方根）, 可知 $\mathrm{R} 2=0.950$, 调 整的 $R 2=0.936$, 并且通过了 $F$ 检验

$(F=66.880)$ 和显著性检验, 表明整 体模型结果可行（见表 4)。所得到的 回归模型为:

$$
\begin{aligned}
& Y^{*}=0.470 F_{1}+0.133 F_{2} \\
& t=(11.445)(2.584)
\end{aligned}
$$

(3) 将主成分的表达式 (1) 式和（2） 式带入 (3) 式, 计算得到回归系数如 下:

$$
\beta=\left[\begin{array}{cc}
-0.211 & 0.821 \\
0.475 & -0.019 \\
0.415 & 0.270 \\
-0.442 & -0.185 \\
0.444 & 0.283 \\
0.406 & -0.330
\end{array}\right]\left[\begin{array}{l}
0.470 \\
0.133
\end{array}\right]=\left[\begin{array}{c}
-0.010 \\
0.221 \\
0.231 \\
-0.232 \\
0.246 \\
0.147
\end{array}\right]
$$

通过整理最终建立的关于标准化自变 量的回归模型为:

$$
\begin{aligned}
& Y^{*}=-0.010 X_{1}^{*}+0.221 X_{2}^{*}+0.231 X_{3}^{*} \\
& -0.232 X_{4}^{*}+0.246 X_{5}^{*}+0.147 X_{6}^{*}
\end{aligned}
$$

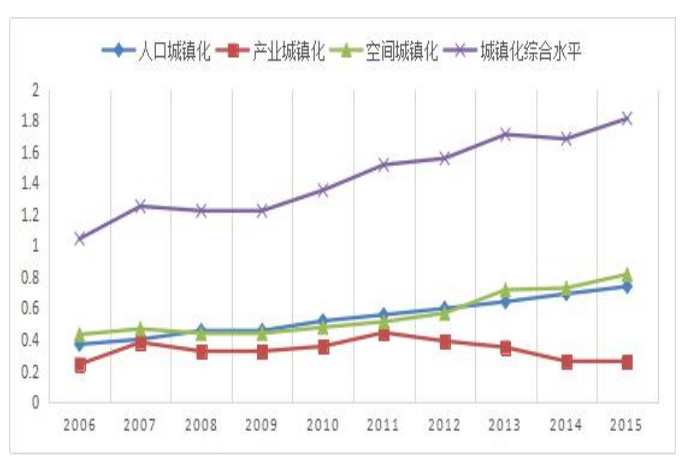

图 1 2006-2015 年人口、产业、空间城镇化 及城镇化综合水平发展趋势

表 3 主成分分析

\begin{tabular}{|c|c|c|c|c|c|c|}
\hline \multirow{2}{*}{ 组件 } & \multicolumn{3}{|c|}{ 初始特征值 } & \multicolumn{3}{|c|}{ 提取载荷平方和 } \\
\cline { 2 - 7 } & 总计 & $\begin{array}{c}\text { 方差百分 } \\
\text { 比 }\end{array}$ & 累积\% & 总计 & $\begin{array}{c}\text { 方差百分 } \\
\text { 比 }\end{array}$ & 累积\% \\
\hline 1 & 4.212 & 70.206 & 70.206 & 4.212 & 70.206 & 70.206 \\
\hline 2 & 1.044 & 17.395 & 87.601 & 1.044 & 17.395 & 87.601 \\
\hline
\end{tabular}


表 4 主成分回归分析

\begin{tabular}{|c|c|c|c|c|c|c|c|}
\hline \multirow{2}{*}{ 变量 } & \multicolumn{2}{|c|}{$\begin{array}{c}\text { 非标准化系 } \\
\text { 数 }\end{array}$} & \multicolumn{2}{|c|}{ 标准化系数 } & \multicolumn{2}{|c|}{ 共线性诊断 } \\
\cline { 2 - 8 } & $\mathrm{B}$ & $\begin{array}{c}\text { 标准 } \\
\text { 误差 }\end{array}$ & 贝塔 & $\begin{array}{c}\mathrm{T} \text { 检 } \\
\text { 验 }\end{array}$ & $\begin{array}{c}\mathrm{P} \text { 值 } \\
\text { 检验 }\end{array}$ & $\begin{array}{c}\text { 容差 } \\
\text { 值 }\end{array}$ & $\begin{array}{c}\text { 方差膨 } \\
\text { 胀系数 }\end{array}$ \\
\hline 常量 & & & & .000 & 1.000 & & \\
\hline $\mathrm{F} 1$ & .470 & .041 & .965 & $\begin{array}{c}11.44 \\
5\end{array}$ & .000 & 1.000 & 1.000 \\
\hline $\mathrm{F} 2$ & .133 & .084 & .133 & 2.584 & .03 & 1.000 & 1.000 \\
\hline
\end{tabular}

\section{3 实证分析结果}

由上述实证分析可知，金融支持 指标对新型城镇化建设的作用程度整 体偏低，且全社会固定资产投资中国 内贷款占比 $\left(X_{4}\right)$ 和金融机构存贷款转 化率 $\left(X_{1}\right)$ 对城镇化综合发展水平

（Y）产生了负向作用，说明金融在支 持城镇化的同时也约束着城镇经济的 发展。首先, 自变量中对城镇化综合 发展水平影响最大的是城镇固定资产 投资额占存款额的比重 $\left(X_{5}\right)$ 和金融机 构存贷款总额占 GDP 的比值 $\left(X_{3}\right)$ ，当 这两个指标增加 $1 \%$, 城镇化水平就会 分别上升 $0.246 \%$ 和 $0.231 \%$, 对新型 城镇化发展做出了相应贡献。其次, 对城镇化发展影响较大的依次是金融 业对 GDP 的贡献率 $\left(\mathrm{X}_{2}\right)$ 和中长期贷款 占贷款余额的比值 $\left(X_{6}\right)$, 这两个指标 每增加 $1 \%$, 城镇化水平就会分别提高 $0.221 \%$ 和 $0.147 \%$ 。最后, 全社会固 定资产投资中国内贷款所占的比值

$\left(X_{4}\right)$ 和金融机构存贷款转化率 $\left(X_{1}\right)$ 对城镇化发展的约束作用较为显著, 这两个指标每增加 1\%, 城镇化水平就 会分别下降 $0.232 \%$ 和 $0.010 \%$, 严重 阻碍了贵州集约高效的新型城镇化发 展。

政策建议：提高金融支持贵州新 型城镇化的有效性，应从金融支持城 镇化进程的各类主导性因素出发, 即 从金融供给的效率、结构和规模三方 面出发, 有重点、有针对性地提高金
融支持贵州新型城镇化的水平和质 量。

\section{参考文献}

[1] 倪鹏飞. 新型城镇化的基本模式、 具体路径与推进对策 $[\mathrm{J}]$. 江海学 刊, 2013, 56 (1) : 87-94.

[2] 吴福象, 沈浩平. 新型城镇化、创新 要素空间集聚与城市群产业发展 $[\mathrm{J}]$. 中南财经政法大学学 报, 2013, 56(4):36-42.

[3] 杨充霖. 资源空间配置与中国新型 城镇化的基础理论构架 $[\mathrm{J}]$. 经济学 动态, 2014, 55 (9) : 98-105.

[4] 陶有之. 新型城镇化: 目标、步 骤、措 施 $[\mathrm{J}]$. 社会科 学, 2013, 35 (9) :34-36.

[5] 王素斋. 新型城镇化科学发展的内 涵、目标与路径 $[\mathrm{J}]$. 理论月 刊, 2013, 35 (4) : 25-28.

[6]黄国平. 促进城镇化发展的金融支 持体系改革和完善 $[\mathrm{J}]$. 经济社会体 制比较, 2013, 29(4):56-66.

[7]彭克强. 论金融支持新型城镇化建 设的原则与配套措施 $[\mathrm{J}]$. 社会科 学, 2014, 36 (3) :62-66.

[8] 陈志伟. 金融发展对城镇化影响的 实证研究一以河南省为例 $[\mathrm{J}]$. 经济 经纬, 2014, 31 (6) :7-13.

[9] 罗琼. 中国金融发展与新型城镇化 建设的关系实证分析 $[\mathrm{J}]$. 经济地 理, 2016, 36 (9):66-71.

[10）李文. 中国西部新型城镇化建 设综合测度及金融支持研究 $[\mathrm{J}]$. 经 济问题探索, 2017, 38(1):72-81.

[11] 方显仓. 新型城镇化发展中的 金融支持机制建设研究 $[\mathrm{J}]$. 经济纵 横, 2013, 29 (12) : 16-20.

[12］邱俊杰. 新型城镇化建设中的 金融困境及其突破 $[\mathrm{J}]$. 理论探 索, 2013, 30 (4) : 82-86. 